\title{
DAKWAH CERDAS ERA GLOBALISASI ANTARA TANTANGAN DAN HARAPAN
}

\author{
Habib Alwi \\ Email: abialwi76@gmail.com
}

\begin{abstract}
Da'wah is intelligent in the sense of being able to build concepts and suitability and contextual in like the development of the era. Thus it must be performed with the Da'wah based on empirical studies and use the multidisciplinary approach. The contributions in this approach were able to answer the challenge and expectation propagation is done in this era of globalization the vendors '.
\end{abstract}

Keyword: Da'wah, intelligent, globalization, challenges and expectations.

\section{A. Pendahuluan}

Dampak dari perkembangan sains dan teknologi, terutama dalam bidang komunikasi, salah satunya adalah globalisasi. Istilah 5F (Fun, Fashion, Food, Facility, dan Fantacy) sudah mengglobal. Fun atau hiburan berbentuk film, CD, VCD, baik dalam bioskop maupun acara televisi dapat disaksikan di seluruh dunia. Lagu-lagu Celine Dion atau Maria Carey dapat didengarkan di bus-bus atau mobil pribadi ataupun di mal-mal dan rumah rumah tempat tinggal.Mode pakaian yang lagi trendy di Eropa dapat dengan cepat dijual dan dipakai oleh anak- anak muda di negara-negara terpencil sekalipun. Dari "belly botton" hingga "you can see" dapat kita saksikan bila kita ke mall-mall atau pusat pertokoan. Makanan ala Mc Donald, KFC, Fizza Hut, semuanya dapat dikonsumsi oleh masyarakat yang menghendakinya. Fasilitas hidup, seperti mobil, mulai dari mercedes benz hingga BMW bertebaran di jalan-jalan raya. Begitu pun fasilitas rumah tangga seperti kulkas, microwave, stove, blender dapat dengan mudah diakses dimiliki oleh rumah-rumah tangga hingga di pedesaan sekalipun. 
Dakwah kemudian memerlukan kecerdasan tertentu dalam rangka menyahuti kondisi seperti ini. Sains dan teknologi dapat membantu kita agar dakwah kita juga ikut cerdas. ${ }^{1}$ Dakwah harus berakar dari kepercayaan akan emprisisme yang sangat kuat. Dakwah juga seharusnya tidak diterjemahkan lagi sebagai sesuatu yang mengarah pada makna seperti: hallo-hallo, propagation, missionary, proselytization. Hal ini, bukan hanya kurang produktif, tetapi malah bisa jadi kontra produktif dan boomerang, karena dakwah Islamiah kemudian dibenci dan ditakuti. Makna dakwah seperti ini bukanlah studi ilmiah atau empiris, karena selalu mulai dengan: Ud'uu ilaa sabiili rabbika. Man ahsanu qawlan min man da'aa ilaa Allaah. Ballighuu ,annii walaw aayah. Kecuali melalui proses reinterpretasi, ayatayat ini semua mengarah kepada Allah yang abstrak itu. Tetapi reinterpretasi emprikal dapat dikemukakan bahwa Allah di sini bermakna jalannya yang mengarahkepadakebaikan, kerja-kerja kemanusiaan, pembangunan ekonomi, temuan sains dan teknologi. ${ }^{2}$

\section{B. Dakwah dan hal-hal Empiris}

Umat Islam diperintahkan untuk menyampaikanpesan-pesanIslamyang terkandung dalam al-Quran. Perintah ilahi ini kemudian dipopulerkan

${ }^{1}$ Muhammad Munir, Metode Dakwah, (Jakarta: Prenada Media, 2006), h. 7.

${ }^{2}$ Ulumuddin, Globalisasi Dan Tantangan Dakwah, Jurnal Almanar Edisi 1, (Versi pdf, 2004), h. 3 . dengan istilah kewajiban berdakwah. Berdakwah dalam Islam bukan saja sebagai kewajiban tetapi juga sebagai sebuah ajaran normatif-universal. Kerana itu, gerakan dakwah selalu saja menghadapi berbagai cabaran, khususnya di era serba kompleks yang tidak lagi memiliki batas-batas wilayah, akibatnya, sudah tidak menjadi penghalang bagi komunitas dunia untuk saling berjejaring dan saling mempengaruhi dan inilah yang disebut dengan era globalisasi. ${ }^{3}$

Permasalahan kajian adalah bagaimanakah cabaran dan peluang dakwah Islamiyyah dalam era globalisasi. Bagaimanakah peran strategis dakwah dapat membangun asumsi yang benar berkaitan dengan karakter manusia moderen yang sudah terglobalkan. Kajian inimenyimpulkan bahawa manusia modern adalah sebuah komunitas baru yang jauh berbeda dengan komunitas muslim yang hidup di zaman awal-awal Islam. Oleh karena itu, gerakan dakwah mesti menempuh cara, metode dan strategi yang baru pula agar iadapat berjalan seiring dengan perkembangan dunia global yang sangat dinamis agar dakwah dapat mudah diterima oleh objeknya seharusnya dakwah bersifat:

1. Studi dakwah seharusnya bersifat empiris

Setidaknya ada dua cara yang dapat ditempuh:

${ }^{3}$ Subhihar dan Indra Kesuma Nasution, dalam tulisannya yang berjudul Dinia Islam di Tengah Globalisasi, Dosen FISIP-USU, h. 36-37. 
a) Menggunakan Ilmu Komunikasi dalam melihat dakwah. Ilmu komunikasi telah berhasil menempa diri menjadi ilmu yang punya koridor tersendiri. Tak dapat dibantah bahwa temuantemuan telekomunikasi sekarang ini beranjak dari filsafat ilmu komunikasi yang percaya kepada empirisisme. Dakwah dapat ditilik dengan menggunakan teori-teori ilmu komunikasi.

b) Dakwah dilihatsebagaimasalah yang bisa dideteksi. Pelaku dakwah, institusi atau lembaga dakwah, pelaksanaan dakwah, proses dakwah, dana dakwah, interaksi dakwah, evaluasi dan analisa dakwah (keuangan)

2. Ilmu Komunikasi mendekati masalah Dakwah

a) Apparent State of Affairs (ASA). as perceived by five levels of analysis. Kondisi real permasalahan komunikasi dapat dilihat berdasarkan analisa lima level: intra-personal, interpersonal, inter-organisasi, inter-environmental, dan interteknologi. Interpersonal dapat mencakup aspek komitmen, konsistensi, transparansi, akuntabilitas, inteligensi, dan komunikatibilitas. Hal ini dapat dikaitkan dengan taqwa, iman, islam, dan ihsan.
Atau lebih jelas lagi shiddiq (komitmen, ke j u j u r a n ), istiqamah (konsistensi), fathanah (inteligensi), amanah (akuntabilitas) dan tabligh (komunikatibilitas).Suasana pelaksanaan dan proses dakwah dapat dianalisis berdasarkan in ter - environ men tal (lingkungan). Suasanakondusif dapat membawa kepada dakwah yang kondusif pula. Jadi kita dapat melihat suasana mesjid atau majelis taklimnya, apakah sejuk, panas, atau dingin; terang atau gelap, luas atau sempit, kotor atau bersih. Adapun komunikasi inter teknologi dapat digunakan untuk mengetahui teknologi apa saja yang menjadi pendukung dakwah. Apakah pelaksanaan dakwahnya didukung dengan teknologi modern seperti, OHP, LCD, VCD, DVD, dst. Ataukah masih menggunakan teknologi konvensional, seperti papan tulis, kapur tulis, dan metode caramah, bukan diskusi.

b) Intended State of Affairs (ISA) as perceived by five levels of analysis. Pada analisis level ini, seperti juga pada ASA di atas, kita dapat melihat nilai-nilai tertentu yang diidealkan. Kita dapat melihat apa saja yang kurang dari lima model analisis itu. 


\section{Dakwa Hendaknya Berlandaskan Pada Studi Empirikal}

Islam, seperti agama lain, sebagai ajaran seringkali menyulitkan bagi peneliti untuk mengkajinya secara akademis, sebab tersimpul makna doktrin normatif yang inheren baik tersurat maupun tersirat dalam teks sucinya. Apa lagi bila penulisnya memasukkan hal-hal transendental (gaib) dan divinity (ketuhanan) menjadi premis judgmental yang diyakininya. Karena itu pertanyaan utama kita adalah bagaimana seharusnya Islam sebagai objek ilmu pengetahuan dikaji? Dengan kata lain, bagaimana mempelajari, meneliti dan menulis kajian keislaman itu?

Oleh karena itu ilmu pengetahuan hendaknya berlandaskan pada studi empirikal, maka Islam seharusnya dikaji menurut fakta dan data yang dapat diverifikasi. Epistemologi, ontologi, dan aksiologi, kemudian, menjadi bingkai berpikirnya. Seorang penulis/peneliti mesti melakukan langkah-langkah penelusuran tentang bagaimana sebuah ajaran itu dielaborasi, tanpa dikaitkan dengan iman atau aqidahnya; serta apa yang menjadipenting ditelitiuntukpelahiran dan penemuan ilmu pengetahuan. Yang terakhir adalah bagaimana suatu temuan menjadi bermanfaat dalam kehidupan keseharian manusia dan lingkungannya.

Pengkajian dilakukan tentunya berdasarkan metodologi tertentu. Dalam ilmu sosial terdapat berbagai macam alat analisis. Sudah lazim kita kenal umpamanya analisis induktif, deduktif, komparatif, dan analogis. Bila induktif berusaha menemukan sesuatu dengan memulai dari yang khusus dan rinci lalu menarik kesimpulan general; maka deduktif adalah sebaliknya, yakni dari general ke detail partukular. Bebeda dari komparatif yang menekankan aspek perbandingan pada sifatnya, maka analogi menarik dari aspek perbandingan pada fenomena dan gejala alam.

Ilmu-ilmu sosial lainnya telah melahirkan berbagai macam pisau analisis. Ilmu komunikasi misalnya telah sukses merajuk beberapa alat kajian seperti analisis isi (content analysis), frame (bingkai) analysis, path (jalur) analysis, discursive (wacana) analysis, ethnomethodological (bahasa keseharian) analysis, atau focus (fokus) group analysis, dll.

\section{Komunikasi Sebagai Alat Inter- displiner Kajian Keislaman}

Dalam studi ilmu komunikasi, dikenal dengan siapa sumber informasi (source, sender), pesan (message), saluran (channel), penerima (receiver), serta efek (effect). Apabila konsepkonsep ini coba diaplikasikan dalam kajian keislaman, maka kita akan melihat satu persatu apa yang menjadi relevan dan sepadan dengan konsep Islam. Seorang penulis kemudian dapat mengkajinya menurut konsep yang dipilihnya. 
Apabila meneliti aspek source (sumber) informasi ajaran Islam, maka seseorang peneliti seharusnya dapat mengambil Allah dan sifat-sifatNya sebagai objek kajian. Kemudian apakah ini boleh atau dibolehkan oleh Islam? Bagi yang menggunakan hadits "tafakkaruu fi khalqi Allah, wa laa tafakkaruu fi al-khaliq" (bahwa silakan Anda pikirkan ciptaan Allah tapi jangan sekali-sekali pikirkan Penciptanya (Allah), maka tentu tak ada lagi jalan untuk mempelajarinya. Jadi di sinilah masalahnya. Namun, kita dapat angin segar dari teologi, yakni ilmu tentang ketuhanan yang membahas tentang sifat, zat, dan hakikat Tuhan. Ilmu kalam dan filsafat pun kerap menggariskan koridor keilmuan pada aspek-aspek divinitas pencipta alam ini, tentang bagaimana Ia dipahami manusia.

Dengan demikian yang dikaji tentang Tuhan sebagai sumber (source) adalah pendapat aliran filosof, kalam dan teologi yang ada dalam Islam. Seorang penulis pun terbebas dari doktrin judgemental agama Islam. Kalau toh harus ada keberpihakan, tentunya, seorang penulis akan tetap memberikan rujukan yang empirikal, umpamanya menunjukkan kitabnya (referensinya). Sikap kritis penulisnya tetap dituntut demi kualitas temuannya.

Sekarang bagaimana mengkaji ajaran Islam dari segi pesan (message) nya?Pesan-pesanutamaIslamtersimpul di dalam kitab suci Al-Qur'an. Nabi Muhammad pun meninggalkan pesan yang tertulis dalam bentuk hadits. Kemudian para penerusnya pun melakukan prosesijtihad, penelusuran, skrutinitas, yang kemudian melahirkan karya-karya monumental dalam Islam, yang semuanya bisa dikaji secara message analysis. Berbagai macam cara pengkajian yang dapat dilakukan. Seorang penulis bisa menggunakan penelitian tafsir. Pendekatannya pun beragam, bisa dengan cara bi al-ra'yi atau bi al-ma'tsur, yang sudah populer sejak zaman klasik. Bahkan bisa juga dengan pendekatan takwil atau hermeneutika, semiotika, semantik, syntaksis, dll. Yang penting bagaimana seorang penulis tetap menjaga agar data yang digunakan valid, serta interpretasi dan analisisnya koheren. Di sinilah kemudian terkadang terdapat kejanggalan, bila aqidah ikut terlibat dalam penarikan kesimpulan penafsiran Qur'an, ketika hal-hal yang non-empirikal menjadi hujjah. Ayat-ayat pun menjadi pembenaran argumentasi, padahal bukan kajian tafsir.

Dengan cara ini, maka ilmu-ilmu humaniora dan keadaban mendapat angin segar yang pada gilirannya bisa mengembangkan atau membangun temuan unik. Ilm al-arudhi, naqd al-adabi, balaghah, misalnya, bisa mendapatkan nuansa dan metodologi interdisipliner dari ilmu komunikasi, dengan mengadopsi discursive, intertextual, semiological analyses.

Studi source (sumber) ini dapatjuga meneliti kemalaikatan dan kerasulan, prihal bagaimana pendapat para ahli 
kalam dan teologi tentang keduanya. Para ulama dan pendiri mazhab pun bisa dikaji dengan pendekatan sumber ini. Asal usul, serta latar belakang pendidikan, keluarga, serta pikirannya sungguh akan menarik untuk dikuak.

Studi message (pesan) tentang hadits juga tetap menjadi penting. Al-Kutub al-Sittah atau al-Sab'ah dan kitab para mazhab hukum Islam yang ada baik dalam tradisi Sunni maupun Syiah merupakan objek yang tetap relevan untuk dikaji. Selain approach di atas, bisa juga hadits didekati dengan menggunakan content analysis, discursive analysis, path analysis. Berbeda dengan tradisi klasik yang melihat hadits dari segi asbab alwurudnya, atau sanad dan matannya, tradisi interdisipliner komunikasi dapat melihat hadits dari segi isinya (temanya) bagaimana hadits itu dikonstruksi. Atau dengan pendekatan wacana dengan melihat hadits dari segi diskors antara hadits yang satu dengan yang lainnya. Sedang path analysis bisa melihat hadits melalui alur penyampaiannya.

Pesan lain yang dapat dikaji, selain rukun iman seperti di atas, adalah rukun Islam. Membicarakan hal ini memang amat riskan, karena berkaitan dengan ibadah mahdhah yang diyakini umat Islam sebagai sesuatu yang tak bisa berubah. Namun demikian, masih terbuka kemungkinan menelitinya dari segi tematik dari ayat-ayat atau hadits tentang syahadat, shalat, puasa, zakat dan haji. Perbedaan antara mazhab yang satu dengan yang lainnya tentu ada dan menarik untuk dikaji lebih jauh. Kalau sama, mengapa kemudian lahir mazhab? Ilmu perbandingan mazhab nampaknya belum begitu berkembang. Padahal metodologi komparatif dalam ilmu sosial sudah cukup lama dikenal di dunia Islam.

Pesan yang disampaikan oleh seorang ulama atau pembicara melalui media komunikasi baik printed media (media cetak) atau electronic media (media elektronik) dapat dikaji dengan analisis isi (content), bingkai (frame), atau jalur (path), dengan dituntun dengan teori konstruksi dalam ilmu komunikasi yang sarat interdispliner ini.

Penerima ajaran atau dakwah (recipient) adalah pendekatan yang juga tak kalah pentingnya dalam kajian interdisipliner. Seorang penulis bisa dengan pendekatan historical analysis (analis sejarah) mempelajari sahabat nabi sebagai penerima langsung ajaran nabi, dst. Jamaah dari aliran tertentu dalam Islam bisa diteliti dengan menggunakan audience analysis (analisis pendengar). Apa lagi bila memang meneliti soal dakwah Islam melalui radio, televisi, atau teater/film, maka analisis khalayak sungguh amat relevan. ${ }^{4}$ Program pemerintah di dunia Islam bisa diteliti reaksi orang Islam terhadapnya, dengan menggunakan pendekatan ethnomethodology. Yaitu pendekatan yang menekankan pada common sense knowledge atau local knowledge (pengetahuan lokal),

${ }^{4}$ Burhan Bungin, Konstruksi Sosial Media Massa,( Jakata: Kencana, 2004), h.48. 
melalui bahasa keseharian suatu masyarakat tertentu. ${ }^{5}$

Pendekatan lain yang relevan adalah communitarian approach, yang menekankan pada analisis komunitas Muslim berhadapan dengan komunitas lainnya. Prosesnya adalahbagaimana suatu komunitas mendefinisikan dirinya sendiri; kemudian bagaimana komunitas tersebut mendefinisikan komunitas lain dan akhirnya, bagaimana seorang peneliti mendefnisikan kedua definisi tersebut. Terakhir adalah pendekatan effect (pengaruh). Seorang peneliti akan memperhatikan sejauh mana pengaruh sebuah ajaran, doktrin, organisasi, institusi atau seorang da’i terhadap masyarakat Islam tertentu. Masyarakat tersebut akan dibandingkan bagaimana keadaan sebelumnya dengan keadaan sesudah mengikuti suatu program tertentu. Ataukah sebaliknya, bagaimana seseorang figur terkenal membuat sebuah media popular. Bisa dengan cara wawancara, bisa juga dengan pendekatan ethnography, ethnology sebagai cabang dari antropologi, dengan terlibat langsung pada kegiatan da'i tersebut. Jadi participant observation menjadi pilihan tepat dalam hal ini. Pertanyaan yang biasa diangkat adalah siapakah yang aktif dalam pembentukan perubahan atau pengaruh, apakah penerima atau pengirim. ${ }^{6}$

\footnotetext{
${ }^{5}$ Muis, Komunikasi Islami, (Bandung: PT Remaja Karya, 2001), h. 9.

${ }^{6}$ Ibid,. h. 19.
}

\section{Daftar Pustaka}

Muhammad Munir, Metode Dakwah, (Jakarta: Prenada Media, 2006.

Ulumuddin, GlobalisasiDan Tantangan Dakwah, Jurnal Almanar Edisi 1, Versi pdf, 2004.

Mansour Fakih, Sesat Pikir Teori Pembangunan dan Globalisasi, Yogyakarta: Insist Press, 2001.

Badri Yatim, Sejarah Peradaban Islam,Jakarta : PT Raja grafindo Persada, 2008

Ahmad Efendi, Indonesia dalam Arus Globalisasi Neoliberal, Mataram:CV. Dimensi Raya 2010 ,

Yusuf al-Qardhawi, Islam dan Globalisasi Dunia, Jakarta: CV. Pustaka Al-Kautsar, 2001.

Subhihar dan Indra Kesuma Nasution, dalam tulisannya yang berjudul Dunia IslamdiTengah Globalisasi, Dosen FISIP-USU.

Burhan Bungin, Konstruksi Sosial Media Massa, Jakata: Kencana, 2004.

Muis, Komunikasi Islami, Bandung: PT Remaja Karya, 2001. 